\title{
HIDROGEOQUÍMICA DAS ÁGUAS SUBTERRÂNEAS NO MUNICÍPIO DE LENÇÓIS, BAHIA, BRASIL
}

\author{
MATTOS, J.B. ${ }^{1 *}$; CRUZ, M.J.M. ${ }^{1} \&$ PAULA, F.C.F. ${ }^{2}$ \\ 1. Programa de Pós-Graduação em Geologia, Instituto de Geociências, Universidade Federal da Ba- \\ hia (UFBA). Salvador, Brasil. \\ 2. Núcleo de Bacia Hidrográfica, Departamento de Ciências Agrárias e Ambientais, Universidade \\ Estadual de Santa Cruz (UESC). Ilhéus, Bahia, Brasil. \\ ${ }^{*}$ Corresponding author: jon.geociencia@gmail.com
}

\begin{abstract}
Mattos, J.B.; Cruz, M.J.M. \& Paula, F.C.F. (2015). Hidrogeoquímica das águas subterrâneas no município de lençóis, Bahia, Brasil. Braz. J. Aquat. Sci. Technol. 19(2). eISSN 1983-9057. DOI: 10.14210/bjast.v19n2. This study aimed to point out the hydrogeochemistry groundwater in the municipality of Lençóis, State of Bahia, Northeast of Brazil, to classify them according to the content and types of dissolved salts. To this, twenty sampling points were listed in the groundwater in aquifers formed by metasediments, detritical covers and limestones, with the purpose of analyze the following parameters: electrical conductivity, temperature, $\mathrm{pH}$, turbidity, total dissolved solids, $\mathrm{HCO}$, $\mathrm{PO} 4, \mathrm{SO} 4, \mathrm{Cl}-, \mathrm{NO} 3, \mathrm{Na}+, \mathrm{K}+, \mathrm{Ca} 2+$, $\mathrm{Mg} 2+, \mathrm{Fe} 3+, \mathrm{Mn} 4+, \mathrm{Sr} 2+$ and Ba2+. The results showed that the groundwater in the municipality of Lençóis are distributed into two zones with different hydrogeochemistry, one of the largest controlled by geological clastic metasedimentary rocks typologies (sandstones, quartzites, conglomeratics, detritical covers) where the process of water-rock interaction allows occur little quantity salt water, slightly acidic, sweet, soft and predominantly sulfated sodic. The other zone is controlled by chemical metasedimentary rocks (limestones) as well as bicarbonates, where they occur hard water, slightly alkaline, sweets and sulfated calcic and mixed. The levels of metals and elements nitrate, phosphate and sulfate presented themselves generally at low concentrations, with some deviations detected in points of the urban area.
\end{abstract}

Keywords: Chapada Diamantina, Groundwater quality.

\section{INTRODUÇÃO}

As águas subterrâneas nos dias atuais são importantíssimas para inúmeros setores da sociedade, como indústria, agropecuária e abastecimento humano, além de serem parte essencial do meio natural, já que participam ativamente do ciclo hidrológico e de processos geológicos. De forma geral segundo ANA (2005) este tipo de água apresenta excelente disponibilidade e qualidade estando apta para consumo humano, muitas vezes apenas empregando métodos simples de desinfecção.

Estas águas estão confinadas em formações geológicas denominadas aquíferos, ocupando grandes espaços em diferentes tipologias rochosas. Stallard \& Edmond (1983) procuram estabelecer em estudos de aquíferos e rios uma relação entre a geologia (litologia) de uma área, os processos de intemperismo químico com as diferentes constituições iônicas das águas, exercendo um controle sobre a química dos recursos hídricos.

Sendo assim, a influência de fatores naturais na qualidade das águas é na maioria das vezes determinante na definição de água apta para usos primários e secundários. Acrescido a esta condição natural dos aquíferos há a interferência humana que implica em mudanças das características químicas das águas, conforme expõe Conboy \& Goss (2000). Segundo
Conceição et al. (2014) uma grande preocupação, nos dias de hoje, em relação à água subterrânea, é a sua contaminação, pois mesmo o solo tendo a capacidade de imobilização de grande parte das impurezas, essa capacidade é limitada.

Estudos em geoquímica de águas subterrâneas buscam responder questões sobre a caracterização e o comportamento dos processos vinculados a hibridez das concentrações naturais de determinados constituintes. Considerando tal condição dos estudos hidrogeoquímicos, Vivona et al. (2007) afirma que dessa forma é possível estabelecer medidas e ações preventivas e mitigadoras capazes de reduzir os riscos de contaminação para uma população que consome determinado recurso hídrico, evitando danos à saúde pública.

A tipologia geológica de uma região, por muitas vezes, atribui as águas uma assinatura hidrogeoquímica anisotrópica, sujeita a alterações de sua qualidade, como acontece em regiões costeiras e em áreas de contato entre diferentes tipos de aquíferos. Du et al. (2015) e Kaplan \& Muñoz-Carpena (2014) mostraram o dimensionamento da intrusão salina com uso de ferramentas especificas (modelagens e isótopos) em aquíferos de águas doces que representam bem as influências naturais e antrópicas de mudanças nas características da água.

A região da Chapada Diamantina, no estado da 
Bahia, notavelmente é muito rica em recursos hídricos, um território constituído por muitas nascentes, rios de boa vazão, com águas de boa qualidade ambiental, precipitação anual com volumes medianos e tipologia geológica (granular, fissural e cárstica) apta a armazenar significativos volumes de água em subsuperficíe. Aliada a esta condição, as unidades de conservação mantidas na região, as baixa taxas de urbanização e os índices de atividades agropecuárias mesmo que crescentes, porém ainda relativamente baixos, ajudam a assegurar os bons índices hídricos deste território. O objetivo deste trabalho é classificar as águas subterrâneas no município de Lençóis, estado da Bahia, de acordo com a hidrogeoquímica dos aquíferos no território municipal, podendo dessa forma aferir a qualidade da água em virtude do uso e da legislação vigente.

\section{MATERIAIS E MÉTODOS}

\section{Área de Estudo}

A área pesquisada localiza-se no município de Lençóis, porção central do estado da Bahia, na borda leste da Chapada Diamantina, entre as coordenadas geodésicas $12^{\circ} 09^{\prime} ; 12^{\circ} 38^{\prime} \mathrm{S}$ e $41^{\circ} 08^{\prime} ; 41^{\circ} 30^{\prime} \mathrm{W}$ (figura 1). O domínio municipal é de $1.277 \mathrm{Km}^{2}$ e sua sede possui uma altitude de 400 metros. Hidrologicamente faz parte da Bacia Hidrográfica do Rio Paraguaçú, sendo uma região que abriga múltiplas nascentes e cursos d'água cujos principais são o Rio Santo Antônio, Rio Utinga, Rio São José e Rio Bonito.

O clima da borda leste é do tipo cwb (tropical de altitude) na classificação de Koppen (1948), apresenta duas estações bem definidas com precipitação média anual oscilando entre $830 \mathrm{~mm}$ a $1192 \mathrm{~mm}$ (Giulietti et

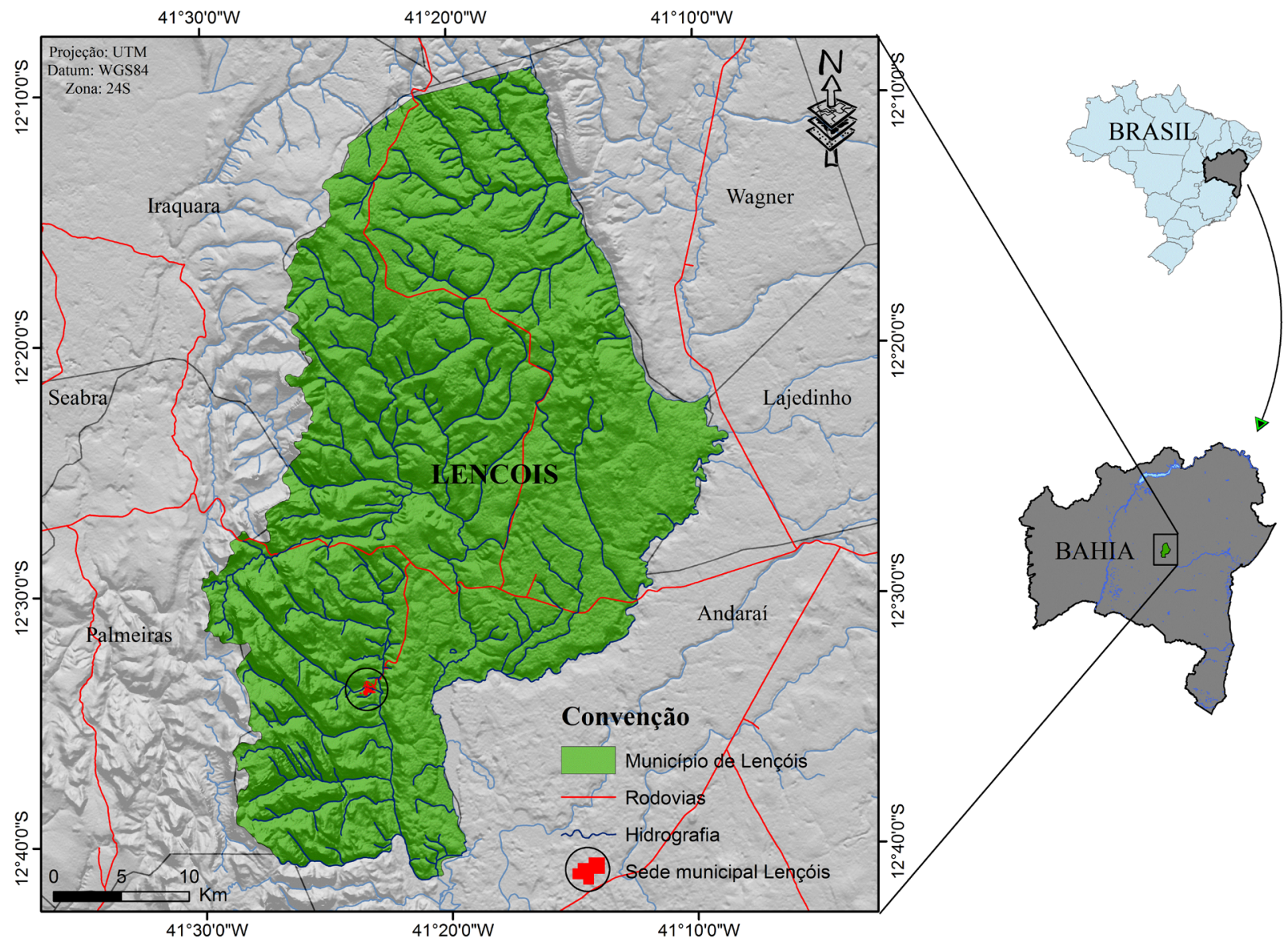

Figura 1 - Mapa de localização do município de Lençóis, Bahia. Fonte de dados: Ibama/Siscom(2007).

al.,1996). De acordo com Barreto (2010), por conta de uma barreira orográfica denominada Serra do Sincorá, a borda leste da Chapada Diamantina está condicionada a valores pluviométricos superiores aos encontrados na região. Configura-se como uma área de transição entre os biomas Mata Attântica, Caatinga e Cerrado, apresentando peculiaridades diversas de diferentes meios morfoclimáticos.

A geologia está condicionada por litótipos diversos como metarenitos, conglomerados, quartzitos, siltitos, arenitos, pelitos, argilitos, calcarenitos. Estes litótipos estão contidos nos grupos; Chapada Diamantina (Formações Tombador, Caboclo e Morro do Chapéu) originado na Era Mesoproterozóica, que 
dispõe de domínio estratigráfico de rochas quartzíticas e areníticas de grande espessura e relativa variabilidade, com a presença de intervalos estratigráficos de sedimentação psamítica (Turra, 2014); Paraguaçú (Formação Açuruá) composta predominantemente por ardósias e metassiltitos da Era Paleoproterozóica; Una (Formações Bebedouro e Salitre) constituído principalmente por rochas calcárias, dolomiticas e peliticas da Era Neoproterozóica. Coberturas quaternárias do tipo areia com níveis de argila e cascalho, crosta laterítica, e depósitos aluvionares recentes (areias com intercalações de argilas e cascalhos) ocorrem na porção Sul do município. (CPRM 2005).

As águas subterrâneas são residentes em domínios hidrogeológicos distintos: i) formações superficiais Cenozóicas, ii) sedimentos clásticos dos Grupos Chapada Diamantina/Estância/Juá (predominante, ocupando cerca de $85 \%$ da área), iii) carbonatos/metacarbonatos do Grupo Una - Formação Salitre e iv) metassedimentos/metavulcanitos do Grupo Una - Formação Bebedouro, (CPRM 2005).

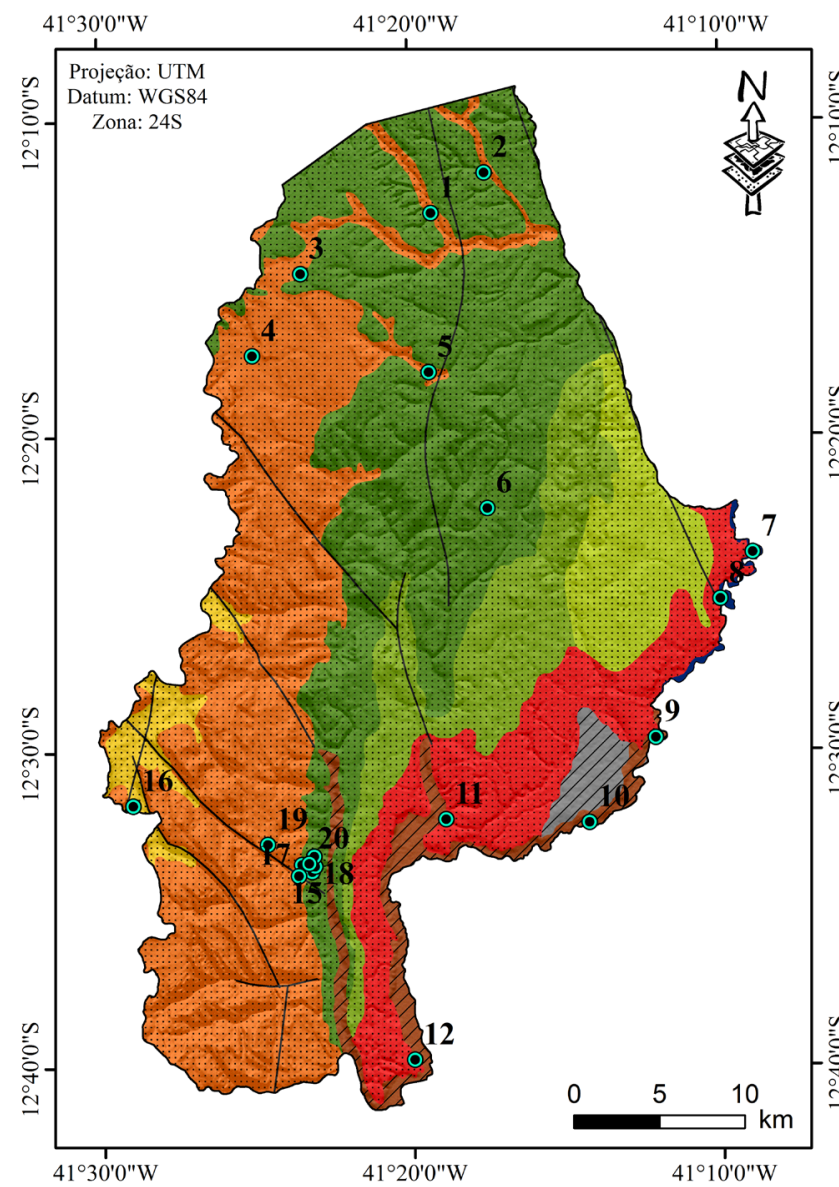

\section{Amostragem}

A campanha de campo e amostragem foi realizada em época de elevada precipitação no município, entre meados do mês de novembro até o mês de fevereiro. Este período é comprovadamente o mais úmido, de acordo com os dados históricos de precipitação do município coletados pelo INMET e tabulados pela SEI (1999) em um levantamento temporal do balanço hídrico do estado da Bahia.

Foram definidos vinte pontos para coleta de amostras de águas subterrâneas através de poços tubulares (figura 2), os quais apresentam uma profundidade média de 84 metros. O critério adotado para definição dos pontos foi a disponibilidade dos poços. A coleta foi feita de acordo com o manual prático de análise de água (FUNASA, 2006) e com os métodos internacionalmente padronizados pelo Standard Methods for the Examination of Water and Wastewater (APHA, 2012). Em etapa pré-campo houve a lavagem e descontaminação dos frascos de polietileno usados na amostragem, onde toda a frascaria foi deixada no banho com detergente Extran não fosfatado a 5\% por 24 horas, na sequência foi deixado no $\mathrm{HNO} 3$ a 2,5\% e por fim enxaguados com água deionizada.

\section{Convenção}

$\square$ Municipio de Lençóis

- Pontos de amostragem (Poços)

\section{Hidrogeologia}

Domínio dos Metassedimentos (Aquifero misto - Granular e Fissural)

1/, Domínio das Coberturas Detrititicas (Aquifero Granular)

4 Domínio dos Calcários (Aquífero Cárstico)

\section{Geologia (Litologia)}

$\checkmark 3$ Areia, Argila e Cascalhos

3 Arenitos e Metarenitos

3 Arenito, Conglomerado suportado por Clastos e Matriz, Quartzitos

3 Arenito, Conglomerado, Conglomerado suportado por Matriz, Quartzito

3 Arenito, Conglomerado, Folhelho, Siltito

4 Argilito, Calcarenito, Quartzito, Ritmito, Siltito

03 Calcarenito, Calcilutito, Carbonato Oolitico

$\checkmark$ Diamictito, Grauvaca, Quartzito

Sedimento Detrito-Lateritico

$\backslash$ Falhas

Figura 2 - Mapa de pontos de amostragem e sínteses litológica-hidrogeológica. Fonte de dados: Ibama/Siscom (2007). 
Dos vinte poços elencados para amostragem dezessete são providos de bomba, nestes poços a coleta das amostras foi feita após vazamento em torno de 5 a 7 minutos, para que não fossem coletadas águas estagnadas na coluna do poço. Nos outros três poços, que não dispunham de bomba, a coleta de água foi feita com o uso de bailer de $1 \mathrm{~L}$, tendo o cuidado de descartar uma quantidade mínima necessária de água estagnada na coluna do poço, na busca de uma água fresca do aquífero. Os parâmetros físicoquímicos medidos em campo foram temperatura, condutividade elétrica, sólidos totais dissolvidos, $\mathrm{pH}$, oxigênio dissolvido e turbidez, todos estes obtidos através de aparelho medidor multiparâmetros Horiba U50, devidamente calibrado.

As amostras coletadas foram conservadas à baixas temperaturas em frascos de polietileno de 1 $\mathrm{L}$ acondicionados em caixas de isopor com gelo e transportadas até o Laboratório de Plasma do Instituto de Geociências da UFBA, nesta instituição foram mantidas em refrigeração à $4^{\circ} \mathrm{C}$ até a realização das análises. Para determinar o sulfato, o nitrato, fosfato, alcalinidade e cloreto, as amostras, com um volume de $1 \mathrm{~L}$ foram filtradas no próprio ponto de amostragem com o uso de bomba manual de vácuo e membrana Milipore 0,45 $\mu \mathrm{m}$. Para os metais, usou-se a mesma frascaria para um volume de $1 \mathrm{~L}$ de água e o mesmo tipo de membrana para filtração, preservou-se em HNO3 concentrado.

\section{Etapa Laboratorial}

As análises realizadas em laboratório seguiram as orientações técnicas do Standard Methods for the Examination of Water and Wastewater (APHA, 2012). Os ânions nitrato, sulfato e fosfato foram obtidos pelo método de absorção molecular de radiação monocromática em uma das regiões do espectro eletromagnético por espectrofotometria óptica através do espectrofotômetro (HITACHI, modelo U-5100). Para o nitrato e sulfato usou-se os kits de bancada da Hach ${ }^{\circledR}$ (NitraVer5 e Sulfaver4) pelo método de redução de cádmio e pelo método turbidimétrico de sulfato de bário, respectivamente. $O$ fosfato foi lido através do método do ácido ascórbico originando um complexo misto de molibdato de amônio. A alcalinidade foi quantificada pelo método de titulação com Ácido Sulfúrico (H2SO4) 0,02 N e o cloreto através do método volumétrico de Mohr, onde os íons cloreto são titulados com solução padronizada de nitrato de prata (AgNO3) $0,01 \mathrm{~N}$, na presença de cromato de potássio (K2CrO4) como indicador (APHA, 2012).

Foram determinadas as concentrações dos cátions $\mathrm{Na}+, \mathrm{K}+, \mathrm{Mg}+, \mathrm{Ca}+, \mathrm{Ba}+, \mathrm{Sr}+, \mathrm{Mn}+$ e $\mathrm{Fe}+$ por Espectrometria de Emissão Atômica com Plasma Indutivamente Acoplado (ICP-OES) no Laboratório de
Estudos do Petróleo - LEPETRO, Núcleo de Estudos Ambientais - NEA, Instituto de Geociências da UFBA. A potência do ICP-OES usado é $1.10 \mathrm{Kw}$ e conta com um sistema nebulizador seaspray com câmara de nebulização ciclônica single pass. As linhas espectrais usadas foram: $568,821 \mathrm{~nm}$ para $\mathrm{Na}+, 766,491 \mathrm{~nm}$ para $\mathrm{K}+, 279,8 \mathrm{~nm}$ para $\mathrm{Mg}+, 315,887 \mathrm{~nm}$ para $\mathrm{Ca}+$, 493,408 $\mathrm{nm}$ para $\mathrm{Ba}+, 407,771 \mathrm{~nm}$ para $\mathrm{Sr}+, 257,61$ $\mathrm{nm}$ para $\mathrm{Mn}+$ e $238,204 \mathrm{~nm}$ para $\mathrm{Fe}+$. Os limites de determinação foram os seguintes: 0,03 para $\mathrm{Na}+, \mathrm{K}+$, $\mathrm{Mg}+, \mathrm{Ca}+\mathrm{Ba}+$ e $\mathrm{Fe}+$, 0,003 para $\mathrm{Sr}+$ e $\mathrm{Mn}+$. Para preparação das curvas de calibração foram utilizadas soluções padrões (Merck S.A) para cada elemento com concentração de $100 \mathrm{mg} \mathrm{L}^{-1}$.

Em posse dos resultados foi utilizado o software ArcGis ${ }^{\circledR}$ versão 10 (ESRI, 2010) para geração de mapas de isovalores da condutividade elétrica e do elemento sulfato, através de geoestatística, usando o método de interpolação das colunas $x$, y e z pela ponderação do inverso da distância, também chamado de IDW (Inverse Distance Weighted) é um método matemático que estima um valor para um local não amostrado como uma média dos valores dos dados da vizinhança. Para classificação das águas pelos íons dominantes e salinidade usou-se o software Qualigraf $®$ versão 14 (Mobus, 2014) através do diagrama de Piper, além da realização do balanço iônico pelos métodos de Custódio e Llamas (1983) e Logan (1965).

\section{RESULTADOS E DISCUSSÕES}

Os parâmetros elencados para classificar as águas dos aquíferos em Lençóis fornecem um bom indicativo para uso destas, porém, vale ressaltar que parâmetros bacteriológicos, principalmente coliformes totais e escherichia coli não foram avaliados, mas que a determinação dos mesmos é de suma importância para aferir a qualidade da água para consumo humano.

Os valores dos parâmetros físico-químicos obtidos são apresentados na tabela 1 . A média registrada da temperatura das águas foi de $25,6^{\circ} \mathrm{C}$, oscilando entre $22,8^{\circ} \mathrm{C}$ e $28,9^{\circ} \mathrm{C}$, variação causada pelas diferenças de profundidade, nível estático e altitude ortométrica dos poços amostrados. A média da condutividade elétrica foi de $152 \mu \mathrm{S} \mathrm{cm}-1$, sendo valores mais elevados nos pontos P7, P8, P9, P10 e P11 (> $200 \mu \mathrm{S} \mathrm{cm-1)} \mathrm{e}$ o valor mínimo o do ponto P5 (32 $\mu \mathrm{S} \mathrm{cm-1).} \mathrm{Esta} \mathrm{os-}$ cilação da condutividade (figura 3) pode ser explicada pelo efeito da litologia na hidrogeologia local, já que os pontos com maior quantidade de sais dissolvidos se encontram em ambientes onde predominam aquíferos de rochas alcalinas (vide figura 2). 


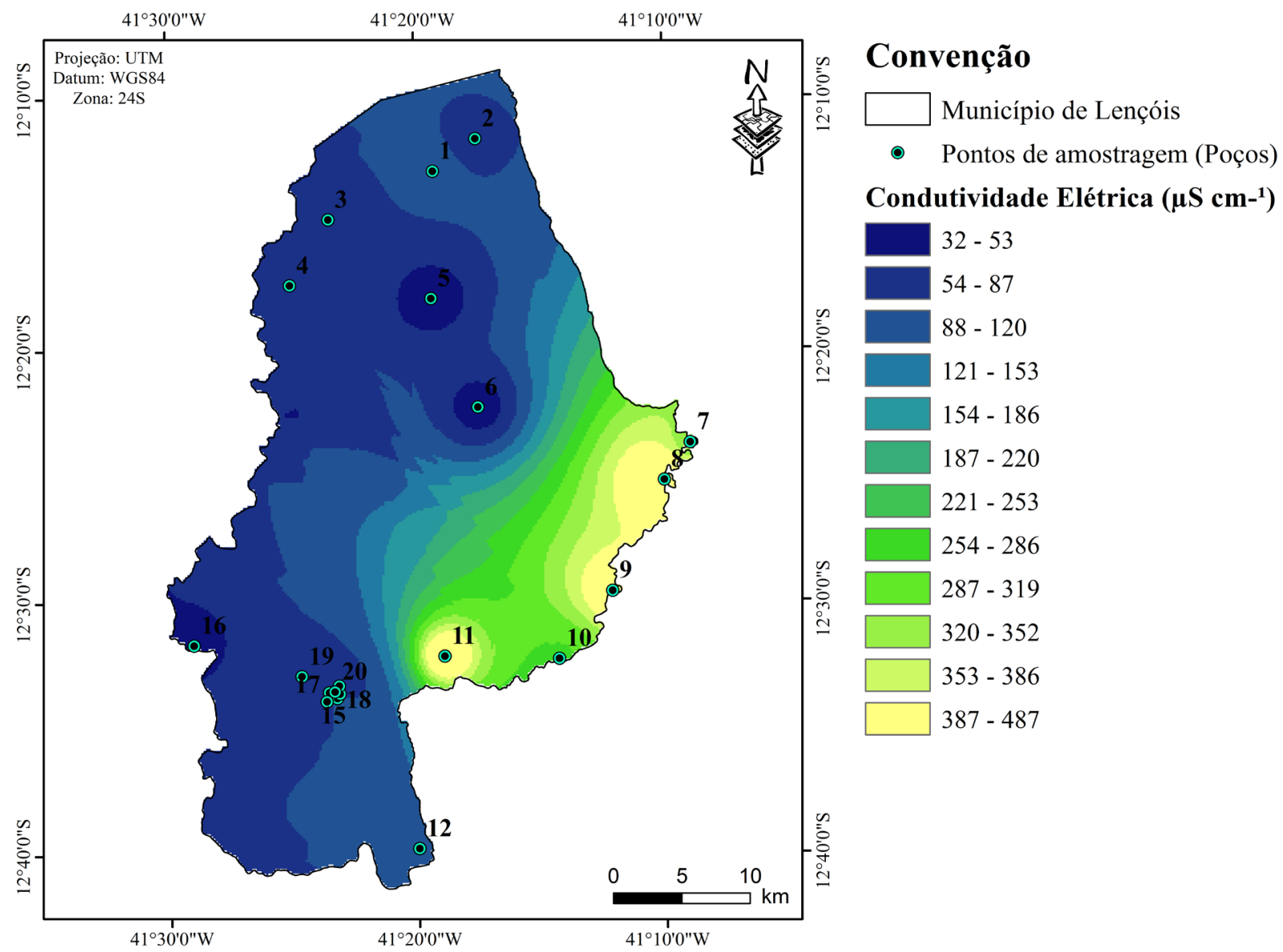

Figura 3 - Mapa de isovalores de condutividade elétrica dos pontos de amostragem com das águas subterrâneas no município de Lençóis.

Tabela 1 - Resultados obtidos dos parâmetros físico-químicos das águas subterrâneas no município de Lençóis-BA.

\begin{tabular}{lcccc}
\hline Poços & C.E $\left(\boldsymbol{\mu} \mathbf{~ c m}^{-1}\right)$ & pH & $\begin{array}{c}\text { Temp } \\
\text { ('C) }\end{array}$ & $\begin{array}{c}\text { Turbidez } \\
(\mathbf{N T U})\end{array}$ \\
\hline P1 & 97 & 5,4 & 24,3 & 0 \\
P2 & 74 & 5,85 & 26,9 & 1,3 \\
P3 & 70 & 5,33 & 24,5 & 4,8 \\
P4 & 59 & 4,83 & 23,2 & 33,1 \\
P5 & 32 & 5,03 & 22,8 & 7,5 \\
P6 & 35 & 4,72 & 24,5 & 9,2 \\
P7 & 334 & 7,07 & 27,5 & 0,5 \\
P8 & 487 & 7,64 & 28,9 & 0 \\
P9 & 435 & 7,75 & 28,2 & 4,7 \\
P10 & 282 & 6,55 & 28 & 182 \\
P11 & 476 & 7,79 & 26,9 & 1,6 \\
P12 & 92 & 5,81 & 27,4 & 709 \\
P13 & 48 & 4,8 & 26,2 & 2 \\
P14 & 191 & 5,23 & 25,9 & 2,3 \\
P15 & 37 & 5,12 & 25,8 & 1,8 \\
P16 & 36 & 4,78 & 20,8 & 4,1 \\
P17 & 47 & 5,54 & 26 & 0 \\
P18 & 35 & 5,03 & 24,8 & 403 \\
P19 & 54 & 5,57 & 24,2 & 0 \\
P20 & 120 & 4,97 & 26,2 & 0 \\
\hline
\end{tabular}

As medidas do $\mathrm{pH}$ apresentaram valor médio de 5,74, caracterizando as águas como ligeiramente ácidas. Os valores do $\mathrm{pH}$ medidos nos pontos $\mathrm{P} 7, \mathrm{P} 8$, P9, P10 e P11 apresentaram uma média de 7,3. Estes números fogem levemente do padrão local, indicando que as águas são levemente alcalinas, com a presença de bicarbonatos que controlam o $\mathrm{pH}$ da água através de suas reações químicas de neutralização dos ácidos, aventando-se uma diferente tipologia geológica de rochas calcárias ricas em minerais de calcita e dolomitas.

A turbidez, no geral, é baixa, destacando-se os de turbidez nula (0 NTU) nos pontos P1, P8, P17, P19 e P20. Foi encontrada turbidez elevada nos pontos $\mathrm{P} 4$, P10, P12 e P18, valores anômalos para o geral dos domínios estudados, as causas prováveis são ligadas aos tipos dos aquíferos (detrítico e cárstico) e principalmente à falhas de engenharia na construção dos poços, sobretudo a falta de revestimento das paredes dos poços. Esta turbidez elevada afeta a qualidade da água, pois, além dos sólidos em suspensão, ela tem a capacidade de reter e camuflar constituintes microbiológicos. 
Mattos, J.B., et al. (2015).: Hidrogeoquímica das águas subterrâneas de Lençóis, Bahia.

\section{Constituintes aniônicos}

Os valores mensurados dos principais ânions dissolvidos estão apresentados na tabela 2. Os pontos P7, P8, P9, P10 e P11 mostraram traços de alcalinidade $\mathrm{HCO} 3 \mathrm{com}$ uma média de $13,7 \mathrm{mg} \mathrm{L-1}$. Tal característica está vinculada a alterações na geologia e comprova a relação com a oscilação observada na condutividade elétrica (vide figura 3 ).

O fosfato se mostrou presente em $75 \%$ das amostras. O valor mais expressivo foi obtido no ponto P11 (45,7 mg L-1), com provável origem ligada à atividades agrícolas que usam fertilizantes contendo fósforo sob a forma de ortofosfato em suas composições, ficando assim retida nas camadas do solo e sujeita a percolação da água em subsuperficíe. Os teores analisados nos pontos P2, P3, P6, P16 e P20 ficaram abaixo do limite de detecção do método analítico utilizado.

O sulfato é o ânion dominante em mais da metade dos pontos amostrados (70\%), a figura 4 ilustra a distribuição do elemento nos aquíferos do território municipal. Os pontos P11 (405 mg L-1) e P14 (516,4 mg L-1) ultrapassaram o valor máximo permitido (vmp) para sulfato estabelecido pela Portaria do Ministério
Tabela 2 - Resultados obtidos para os ânions das águas subterrâneas no município de Lençóis-BA.

\begin{tabular}{llcccc}
\hline Poços & ${ }^{*} \mathrm{HCO}_{3^{-}}$ & ${ }^{*} \mathbf{C l}^{-}$ & ${ }^{*} \mathbf{S O}_{4^{-}}$ & $\begin{array}{c}{ }^{*} \mathbf{N}^{-} \\
\mathbf{N O}^{-}\end{array}$ & $\begin{array}{c}{ }^{*} \mathbf{P}^{-} \\
\mathbf{P O}_{4}^{-}\end{array}$ \\
\hline P1 & 0 & 2,1 & 29 & $<0,1$ & 3,2 \\
P2 & 0 & 3,4 & $<1,0$ & $<0,1$ & $<0,01$ \\
P3 & 0 & 1,7 & 40,5 & 4,7 & $<0,01$ \\
P4 & 0 & 1,7 & 97 & $<0,1$ & 10,9 \\
P5 & 0 & 0,8 & 3,4 & $<0,1$ & 5,5 \\
P6 & 0 & 2,7 & $<1,0$ & $<0,1$ & $<0,01$ \\
P7 & 8,8 & 8,9 & 109 & $<0,1$ & 7,1 \\
P8 & 17,7 & 8 & 195,6 & $<0,1$ & 17,7 \\
P9 & 15,4 & 6,3 & 119 & 3,9 & 15,1 \\
P10 & 8,8 & 5,6 & 107 & $<0,1$ & 4 \\
P11 & 17,7 & 3,8 & 405 & $<0,1$ & 45,7 \\
P12 & 0 & 2,7 & 91 & $<0,1$ & 39,1 \\
P13 & 0 & 1,3 & $<1,0$ & 0,4 & 8,9 \\
P14 & 0 & 6,8 & 516,4 & 5,5 & 4,1 \\
P15 & 0 & 0,8 & $<1,0$ & 1,9 & 0,46 \\
P16 & 0 & 0,01 & 61,7 & 3,1 & $<0,01$ \\
P17 & 0 & 1 & $<1,0$ & $<0,1$ & 2,5 \\
P18 & 0 & 0,4 & 17,8 & 1 & 6,6 \\
P19 & 0 & 1,3 & $<1,0$ & $<0,1$ & 6,4 \\
P20 & 0 & 1,7 & 104,4 & 8,8 & $<0,01$ \\
\hline
\end{tabular}

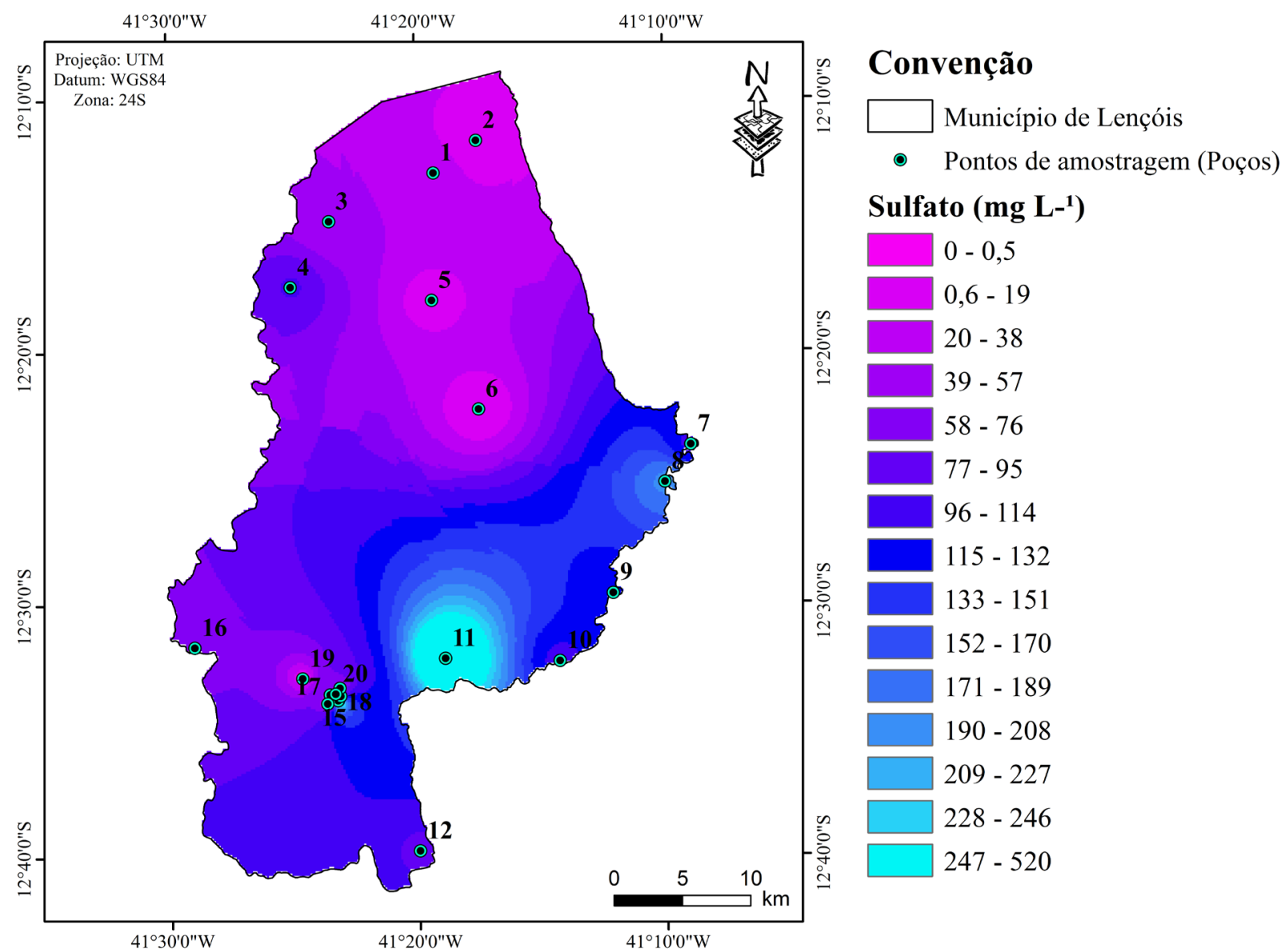

Figura 4 - Mapa de isovalores de sulfato dos pontos de amostragem de águas subterrâneas do município de Lençóis. 
da Saúde 2914/2011 (Brasil, 2011) que é de $250 \mathrm{mg}$ L-1. Segundo Batalha e Parlatore (1977), o sulfato em excesso nas águas subterrâneas (>400 mg L-1) pode causar problemas laxativos e em associação com os íons sódio e magnésio pode provocar distúrbios gastrointestinais severos. A provável origem deste sulfato está associada a depósitos dos minerais gesso e pirita contidos em sessões de solos e rochas em subsuperficíe, no caminho das águas até o aquífero, bem como contaminação por esgotos e águas servidas quando em áreas urbanas. Em seis amostras (P2, P6, P13, P15, P17, P19) o sulfato ficou abaixo do limite de detecção.

Para o cloreto os resultados analíticos indicaram um valor médio de 3,05 mg L-1, bem abaixo do vmp pela Portaria do Ministério da Saúde 2914/2011 (Brasil, 2011) que é de $250 \mathrm{mg} \mathrm{L-1.} \mathrm{O} \mathrm{nitrato,} \mathrm{de} \mathrm{acordo}$ com Murgulet \& Tick (2013) é um dos constituintes mais comuns em águas subterrâneas contaminadas por práticas de uso da terra como urbanização e agricultura. Em concentrações superiores a $10 \mathrm{mg}$ L-1 podem causar distúrbios severos a saúde como metahemoglobinemia e câncer (Hill et al., 1973). Mais da metade das amostras (12) apresentaram valores abaixo do limite de detecção e nenhum dos pontos que indicou ocorrência ultrapassa o vmp da Portaria do Ministério da Saúde 2914/2011 (Brasil, 2011) que é de $10 \mathrm{mg} \mathrm{L}-1$.

A CETESB (2005) considera um valor de $5 \mathrm{mg}$ L-1 para nitrato como base para alertas. Usando como referência esta orientação, nos pontos amostrados do município, dois deles (P14 e P20) apresentaram desconformidade e valores próximos ao vmp pela Portaria 2914/2011 do Ministério da Saúde (Brasil, 2011). Sendo assim, estes pontos devem ser monitorados anualmente e a vigilância sanitária do município deve tomar ciência da situação.

\section{Constituintes catiônicos}

A tabela 3 mostra os resultados obtidos para os cátions nas amostras de água subterrânea do município de Lençóis. O íon sódio apresentou valor médio de $9,1 \mathrm{mg} \mathrm{L}-1$, sendo os pontos P14 (29,2 mg L-1) e P19 (2,5 mg L-1) com a maior e a menor concentração respectivamente. Todos os pontos apresentaram um valor bem abaixo do vmp da Portaria 2914/2011 do Ministério da Saúde (Brasil, 2011) que é de $200 \mathrm{mg}$ L-1 para sódio. A média estabelecida para o potássio foi de 3,6 mg L-1, com variação de concentração entre 0,4 mg L-1 (P6) e 8,7 mg L-1 (P14).

O cálcio nas amostras apresentou uma acentuada assimetria com um valor mínimo de $0,1 \mathrm{mg} \mathrm{L}-1$ (P19) e um valor máximo de $71 \mathrm{mg} \mathrm{L-1} \mathrm{(P11).} \mathrm{Nota-}$ se que os valores aumentam significativamente nos pontos P7, P8, P9, P10 e P11 indicando um desvio
Tabela 3 - Resultados obtidos para os cátions das águas subterrâneas no município de Lençóis-BA.

\begin{tabular}{|c|c|c|c|c|c|c|c|c|}
\hline Poços & ${ }^{*} \mathrm{Na}^{+}$ & ${ }^{*} \mathbf{K}^{+}$ & ${ }^{*} \mathrm{Ca}^{+}$ & ${ }^{*} \mathbf{M g}^{+}$ & ${ }^{*} \mathrm{Ba}^{+}$ & ${ }^{*} \mathrm{Fe}^{+}$ & ${ }^{* \mathrm{Mn}^{+}}$ & ${ }^{*} \mathrm{Sr}^{+}$ \\
\hline P1 & 6,9 & 3,8 & 0,7 & 0,5 & 0,05 & 0,01 & 0,003 & 0,007 \\
\hline P2 & 5,7 & 0,9 & 0,3 & 0,6 & 0,01 & 0,02 & 0,002 & 0,002 \\
\hline P3 & 7,3 & 3,3 & 1,9 & 0,5 & 0,02 & 0,02 & 0,008 & 0,01 \\
\hline P4 & 6,1 & 4,7 & 0,6 & 0,5 & 0,06 & 0,008 & 0,005 & 0,006 \\
\hline P5 & 4,3 & 2,8 & 0,3 & 0,3 & 0,02 & 0,01 & 0,002 & 0,001 \\
\hline P6 & 5,2 & 0,4 & 0,1 & 0,08 & 0,1 & 0,01 & 0,001 & 0,001 \\
\hline P7 & 17,9 & 5,4 & 23,9 & 11,1 & 0,25 & 0,06 & 0,09 & 0,02 \\
\hline P8 & 18,6 & 7,6 & 50,9 & 15 & 0,4 & 0,008 & 0,001 & 0,06 \\
\hline P9 & 13,1 & 6,7 & 43,5 & 16,4 & 0,32 & 0,008 & 0,001 & 0,05 \\
\hline P10 & 15,1 & 2,3 & 23,8 & 8,4 & 0,15 & 0,03 & 0,3 & 0,02 \\
\hline P11 & 14,6 & 4,2 & 71,3 & 5,1 & 0,05 & 3,25 & 0,2 & 0,09 \\
\hline P12 & 13 & 1 & 3,7 & 0,7 & 0,002 & 0,07 & 0,011 & 0,003 \\
\hline P13 & 4,2 & 3,1 & 0,3 & 0,2 & 0,03 & 0,02 & 0,002 & 0,002 \\
\hline P14 & 29,2 & 8,7 & 6 & 1,7 & 0,06 & 0,07 & 0,02 & 0,02 \\
\hline P15 & 3,5 & 5,1 & 0,3 & 0,3 & 0,04 & 0,06 & 0,005 & 0,002 \\
\hline P16 & 4 & 0,6 & 0,1 & 0,3 & 0,005 & 0,06 & 0,001 & 0,001 \\
\hline P17 & 5 & 2,3 & 0,5 & 0,8 & 0,03 & 0,02 & 0,002 & 0,007 \\
\hline P18 & 4,5 & 2,6 & 0,1 & 0,1 & 0,03 & 0,02 & 0,01 & 0,001 \\
\hline P19 & 2,5 & 0,5 & 0,1 & 0,3 & 0,006 & 0,05 & 0,002 & 0,001 \\
\hline P20 & 12,8 & 5,5 & 4,8 & 0,8 & 0,06 & 0,02 & 0,008 & 0,02 \\
\hline
\end{tabular}

causado pela mesma alteração apontada para os valores de alcalinidade nos mesmos pontos. O magnésio pelo comportamento geoquímico similar ao cálcio também ocorreu em maior concentração nos pontos P7, P8, P9, P10 e P11.

Os valores médios de bário, estrôncio, ferro e manganês foram 0,$08 ; 0,01 ; 0,03 ; 0,03 \mathrm{mg} \mathrm{L}-1$ respectivamente. A amostra do ponto P11 extrapolou o vmp da Portaria 2914/2011 do Ministério da Saúde (Brasil, 2011) para ferro e manganês que é 0,3 e 0,1 mg L-1 respectivamente, apresentando concentração de 3,25 mg L-1 de ferro e 0,2 mg L-1 de manganês. $O$ ponto P10 também extrapolou para manganês $(0,3 \mathrm{mg}$ L-1). De acordo com Siah et al. (2005), sobrecargas de ferro ao organismo humano podem causar problemas gastrointestinais, neurológicos e doenças como hemocromatose que pode causar danos ao fígado, pâncreas e coração, além de diabetes. A presença do ferro e manganês nestes pontos é proveniente da dissolução de concreções ferro-manganesíferas, de origem supergênica, acumulado provavelmente em uma camada de calcário alterado do aquífero.

\section{Classificação das Águas}

Para classificar quimicamente as águas subterrâneas no município de Lençóis usou-se o diagrama de Piper (1944) apresentado na figura 5. Constatou-se que $45 \%$ das amostras (9 pontos) são classificadas como águas sulfatadas sódicas, enquanto 30\% (6 pontos) são classificadas como águas cloretadas sódicas, $15 \%$ (3 pontos) como águas sulfatadas cálcicas e apenas $10 \%$ (2 pontos) como águas sulfatadas mistas.

Com os valores de sólidos totais dissolvidos (STD) e condutividade elétrica todas as amostras de águas subterrâneas do município de Lençóis foram classificadas como águas doces (figura 6), seguindo 


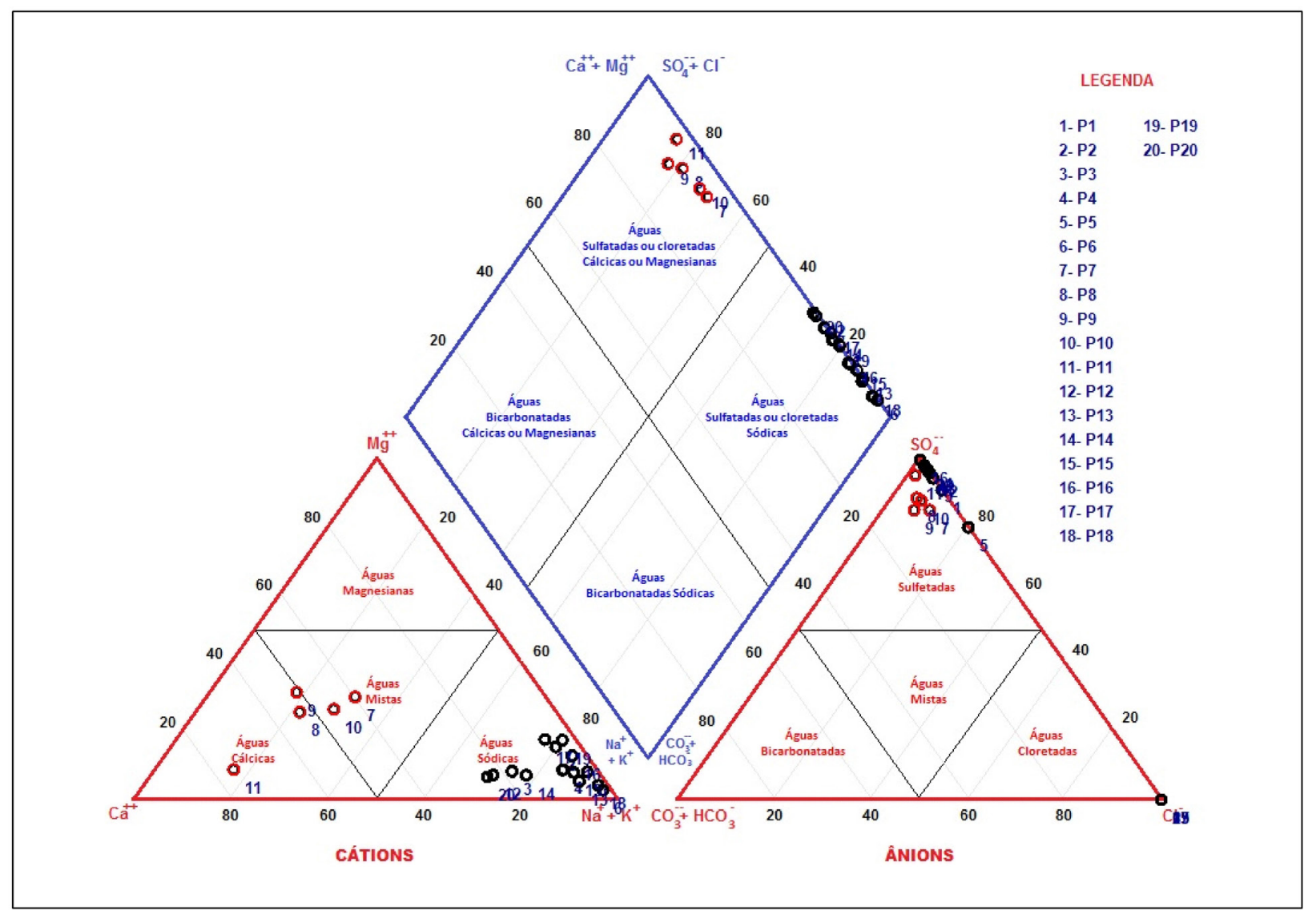

Figura 5 - Diagrama de Piper para as águas subterrâneas do município de Lençóis.

a classificação proposta pela resolução CONAMA 357/2005 (Brasil, 2005) quando estabelece para águas doces o intervalo entre 0 e $500 \mathrm{mg} \mathrm{L-1}$ de STD. Segundo a resolução CONAMA 357/2005 (Brasil, 2005) que dispõe de uma classificação específica para águas doces, as águas subterrâneas de Lençóis apontadas como doces além de estarem habilitadas para consumo humano também estão aptas à proteção das comunidades aquáticas, irrigação de hortaliças e frutas e recreação de contato primário.

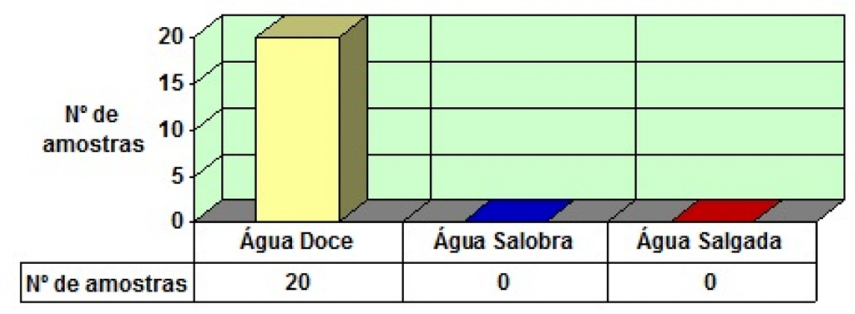

\begin{tabular}{|c|c|}
\hline Tipo de Aguas & $\begin{array}{c}\text { STD } \\
(\mathrm{mg} / \mathrm{L})\end{array}$ \\
\hline Doce & $0-500$ \\
\hline Salobra & $501-1500$ \\
\hline Salgada & $>1500$ \\
\hline
\end{tabular}

Águas com STD superior a $35.000 \mathrm{mg} / \mathrm{L}$ såo consideradas Salmouras (Ex. Aguas marinhas)

Figura 6 - Classificação das amostras de água subterrânea de Lençóis quanto aos sólidos totais dissolvidos - salinidade. Fonte: Mobus, 2014 e Brasil, 2005. 
O artigo $3^{\circ}$ do capítulo II da resolução CONAMA 396/2008 (Brasil, 2008) estabelece seis classificações distintas para águas subterrâneas (Especial, I, II, III, IV e V), levando em conta a concentração dos teores, o valor de referência de qualidade e o valor máximo permitido de cada elemento apresentado nos corpos hídricos. Com base nesta resolução as concentrações iônicas aferidas nas águas subterrâneas de Lençóis apontam para águas de classes Especial, I, II e III, sendo esta última a única classe dentre as elencadas com alteração de sua qualidade por atividades antrópicas, podendo exigir um tratamento específico e adequado.

Em relação a dureza, as águas coletadas nos pontos P7, P8, P9, P10 e P11 apresentaram valores de $94 \mathrm{mg} \mathrm{L}-1$ a $200 \mathrm{mg} \mathrm{L}-1$ sendo classificadas de acordo com Custódio \& Llamas (1983) e Sawyer et al. (2000) como moderadamente duras e duras. As demais águas ( $75 \%$ das amostras) foram classificadas como moles ou brandas, com um valor médio de $5,5 \mathrm{mg} \mathrm{L-1}$.

\section{CONCLUSÕES}

Foi possível concluir que a tipologia geológica dos aquíferos no município de Lençóis, compostas por rochas metassedimentares clásticas e químicas definem duas regiões com diferentes características hidrogeoquímicas. A zona centro-leste do município, dominada por rochas da Formação Salitre apresenta águas mais densas, levemente alcalinas, com maior teor de sais dissolvidos. Em todo o restante do município, onde as rochas fazem parte do Grupo Chapada Diamantina (Formações Tombador, Caboclo e Morro do Chapéu) a hidrogeoquímica predominante nos aquíferos é tipicamente de ambientes clásticos, com reduzida concentração de sais dissolvidos.

As águas subterrâneas dispostas no município de Lençóis são caracterizadas como doces, com baixíssima salinidade, ligeiramente ácidas e pouco turvas. São predominantemente moles, com ocorrências pontuais de águas duras. A concentração de ânions e cátions nas águas é baixa, e estas podem ser classificadas como sulfatadas sódicas e cálcicas e cloretadas sódicas. É importante salientar que em um período climático de estiagem, sem fluxo hídrico de recarga, é provável que esta classificação possa ser alterada, com oscilações principalmente nas concentrações aniônicas, havendo uma inversão entre os sulfatos, cloretos e bicarbonatos.

De forma geral, os elementos nitrato, fosfato e sulfato presentes nestas águas apresentam baixos teores, exceção de pontuais contaminações nas proximidades das zonas urbanas. São águas de classes Especial, I, II e III pela resolução CONAMA e estão aptas para usos primários e secundários, desde que estejam em conformidade com os parâmetros microbiológicos.

\section{AGRADECIMENTOS}

Os autores agradecem a Coordenação de Aperfeiçoamento de Pessoal de Nível Superior (CAPES) pelo financiamento do projeto de pesquisa e pela bolsa de mestrado concedida ao primeiro autor. Ao Programa de Pós-Graduação em Geologia da UFBA e ao Núcleo de Bacia Hidrográfica da UESC pelo suporte técnico e cientifico. A Secretaria Municipal de Meio Ambiente de Lençóis e a Associação de Condutores de Visitantes de Lençóis (ACVL) pelo apoio logístico.

\section{REFERÊNCIAS}

ANA - Agência Nacional de Águas. Panorama da qualidade das águas subterrâneas no Brasil. Brasília, ANA, 2005.

APHA-American Public Health Association. Standard methods for the examination of water and wastewater. 22 th ed. Washington, 2012.

BARRETO, E. A. S. Reconstituição da Pluviosidade da Chapada Diamantina (BA) durante o Quaternário Tardio através de registros isotópicos $(\mathrm{O}$ e $\mathrm{C})$ em estalagmites. 2010. 110 p. Dissertação (Mestrado em Geociências) - Universidade de São Paulo.

BATALHA, B. L.; PARLATORE, A. C. Controle de Qualidade da Água para Consumo Humano: Bases Conceituais e Operacionais. São Paulo: CETESB, 1977. 198p.

BRASIL. Conselho Nacional do Meio Ambiente - CONAMA. Resolução 357, de 17 de março de 2005. Dispõe sobre a classificação dos corpos de água e diretrizes ambientais para o seu enquadramento, bem como estabelece as condições e padrões de lançamento de efluentes, e dá outras providências. Brasília, 2005.

BRASIL. Conselho Nacional do Meio Ambiente - CONAMA. Resolução 396, de 3 de Abril de 2008. Dispõe sobre a classificação e diretrizes ambientais para o enquadramento das águas subterrâneas, e dá outras providências. Brasília, 2008.

BRASIL. Ministério da Saúde. Portaria n 2914/MS, de 12 de dezembro de 2011. Dispõe sobre os procedimentos de controle e de vigilância da qualidade da água para consumo humano e seu padrão de potabilidade, e dá outras providências. Legislação. Brasília, 2011. 
CETESB - Companhia Ambiental do Estado de São Paulo. Decisão de Diretoria n $195-2005$. CETESB, São Paulo, 2005.

CONBOY, M.J.; GOSS, M.J. Natural Protection of Groundwater against bacteria of fecal origin. Journal of Contaminant Hydrology, n. 43, p. 1-24, 2000.

CONCEIÇÃO, F. T; MAZZINI, F; MORUZZI, R. B; NAVARRO, G. R. B. Influências Naturais e Antrópicas na Qualidade da Água Subterrânea de Poços de Abastecimento Público na Área Urbana de Marília (SP). Revista Brasileira de Recursos Hídricos, v. 19, n. 3, p. 227-238, 2014.

CPRM. Serviço Geológico do Brasil. Projeto Cadastro de Fontes de Abastecimento por Água Subterrânea. Diagnóstico do Município de Lençóis, Estado da Bahia. In: VIEIRA, A. T.; MELO, F.; LOPES, H. B. V.; CAMPOS, J. C. V.; GUIMARÃES, J. T.; COSTA, J. M.; BOMFIM, L. F. C.; COUTO, P. A. A.; BENVENUTTI, S. M. P. da (org.). Salvador, 2005. 22p.

CUSTÓDIO, E.; LLAMAS, M. R. Hidrologia subterrânea. 2 ed. Barcelona: Omega, 1983. 2v.

DU, Y.; MA, T.; CHEN, L.; SHAN, H.; XIAO, C.; LU, Y.; LIU, C.; CAI, H. (2015). Genesis of salinized groundwater in Quaternary aquifer system of coastal plain, Laizhou Bay, China: Geochemical evidences, especially from bromine stable isotope. Applied Geochemistry, n. 59, pp.155-165.

ESRI. ArcGIS (Version 10). Los Ángeles, United States: Environmental Systems Research Institute, Inc. 2010.

GIULIETTI, A. M.; QUEIROZ, L. P.; HARLEY, R.M. Vegetação e flora da Chapada Diamantina, Bahia. In: Anais $4^{a}$ reunião especial da SBPC. Feira de Santana, BA, Brasil: 1996, p.144-156.HILL, M. J; HAWKSWORTH, G; TATTERSAL, G. Bacteria nitrosamines and cancer of the stomach. Br. J. Cancer, n. 28, p. 562-567, 1973.

IBAMA. SISCOM. Instituto Brasileiro do meio ambiente e dos recursos naturais renováveis - Sistema Compartilhado de Informações Ambientais. Downloads, ShapeFiles. Brasília, 2007. Disponível em: <http://siscom.ibama.gov.br/shapes/>. Acesso em: 15 de março de 2012.

KAPLAN, D. A.; MUÑOZ CARPENA, R. (2014). Groundwater salinity in a foodplain forest impacted by saltwater intrusion. Journal of Contaminant Hydrology, n. 169, pp. 19-36.
KOPPEN, W. Climatologia con un estudio de los climas de la tierra (transl. P. R. H. Peres), Fondo de Cultura e Economica, Mexico City, Mexico, 1948.

LOGAN, J. Interpretação de análises químicas de água. Recife, U.S. Agency for International Development, 1965. 67 p.

MOBUS, G. Qualigraf. Programa para análise da qualidade de água. FUNCEME. 2014. Disponível em: <http://www.funceme.br/DEHID/index>. Acesso em: 10/09/2014.

MURGULET, D; TICK, G. R. Understanding the sources and fate of nitrate in a highly developed aquifer system. Journal of Contaminant Hydrology, n. 155, p. 69-81, 2013.

PIPER, A. M. A graphic procedure in the geochemical interpretation of water-analyses. Transactions American Geophysical Union, v. 25, p. 914-928, 1944.SAWYER, C. N.; McCARTY, P. L.; PARKIN, G. F. Chemistry for sanitary engineers. $4^{\circ} \mathrm{ed}$. New York, McGraw-Hill, 2000.

SEI. Superintendência de Estudos Econômicos e Sociais da Bahia. Balanço hídrico do estado da Bahia. Salvador. 1999. 250 p.

SIAH, C. W.; TRINDER, D.; OLYNYK, J. K. Iron Overload. Clinica Chimicha Acta, n. 358, p.24-36, 2005.

STALLARD, R. F.; EDMOND, J. M. Geochemistry of the Amazon Basin. 2. The influence of the geology and weathering environment on the dissolved load. Journal of Geophysical Research, Serie C, Washington, DC, v. 88, n. 14, p. 9671-9688, 1983.

TURRA, B. B. Estratigrafia e sedimentologia dos depósitos fluviais pré-vegetação da Formação Tombador (Mesoproterozóico) na Chapada Diamantina Oriental (BA). 2014. 174 p. Tese (Doutorado em Geologia - Geotectônica) Universidade de São Paulo.

VIVONA, R.; PREZIOSI, E.; MADÉ, B.; GIULIANO, G. Occurrence of minor toxic elements in volcanic sedimentary aquifers: a case study in central Italy. Hydrogeology Journal, n. 15, p. 1183-1196, 2007.

Submetido: Maio/2015 Revisado: Junho/2015 Aceito: Agosto/2015 